going to relate to general practice as ordinarily understood? Outside London it was not too difficult to work out a relationship between the general practitioner and the teaching hospital, but within London it sometimes seemed that the closer the practitioner was to the teaching hospital the less was the relationship. He felt it important to develop the idea of a general care scheme for the com- munity in which the teaching hospital and its relation to general practice, and indeed all the health needs of a particular area, could be defined. Otherwise he foresaw a definite weakening in the pattern of general practice.

As things stood at the moment the teaching hospitals in London were going to become increasingly the reserve of super-specialists and the peripheral hospitals were going to grow up without consideration for the functions of the teaching hospital and for the health needs of London. Professor Peart foresaw a chaotic situation developing in ten years' time unless something was done about it.

After the main speeches an interesting discussion followed from the floor.

\title{
MEDICAL HISTORY
}

\section{The First Cystine Stone ?}

William Hyde Wollaston was born in East Dereham, Norfolk, in 1766 and graduated M.B. at Caius College, Cambridge, where he was a lecturer in Greek and Hebrew. He became a physician at Huntingdon and Bury St. Edmunds, and finally moved to London at the age of 31 . He retired from medicine three years later as he was unable to obtain a suitable hospital appointment.

This unusually gifted man discovered a process for making platinum malleable, which won him a fortune. $\mathrm{He}$ also designed the double-image prism which still bears his name, discovered the metal rhodium, and was one of the earliest supporters of Dalton's atomic theory. His contribution to medicine arose from his interest in crystals, which led him to examine calculi. He omitted " no opportunity of paying attention to any urinary concretions to which I could have access."

In 1810 Wollaston, who was the secretary of the Royal Society, gave a classic paper " On Cystic Oxide, a new Species of Urinary Calculus." He described a stone which had been removed from the 5-year-old brother of Dr. Reeve, of Norwich. The boy afterwards developed a second stone and died without submitting to a further operation. The unusual solubility of the stone in both acids and alkalis was noted and also the classical flat hexagonal plates of cystine which formed when a solution of the stone in potash was neutralized by distilled vinegar.
Wollaston had seen only one other specimen, which he believed to be of the same substance, and this was in a collection of calculi given by Mr. Lucas, surgeon of Guy's Hospital, to the Gordon Museum. It had been extracted in the latter half of the eighteenth century from a 36-year-old man named William Small and weighed 270 grains (18 g.). This stone is again mentioned in 1817 by Alexander John Gaspard Marcet, physician and lecturer in chemistry at Guy's Hospital, in his " An Essay on the Chemical History and Medical Treatment of Calculus Disorders," printed by A. Strachan, of London, for Longman, Hurst, Rees, Orme, and Brown.

\section{The Stone}

We thought it would be of interest to examine this stone and (after 200 years) attempt to confirm the nature of the calculus.

Description.- The stone is fragmented, crystalline, and of a light-blue colour.

Chemical Tests.-A fragment of stone was dissolved in dilute hydrochloric acid and submitted to the cyanide/nitroprusside test. ${ }^{2}$ It gave a strong positive reaction for cystine.

Amino-acid Chromatography.-A fragment of the stone was dissolved in acid and then submitted to two-way chromatography on 10-in. (25-cm.) paper, using butanolacetic acid and phenol-ammonia as solvents. ${ }^{3}$ On development with ninhydrin (see Fig.) a spot developed, giving $R_{F}$ values in these solvents identical with those of a known cystine solution.

\section{Conclusion}

Examination of the remaining one of the two stones described by Wollaston in 1810 by the cyanide/nitroprusside test and by amino-acid chromatography confirms his assertion that this stone was indeed a new type of urinary calculus-the first described cystine stone.

We are indebted to Professor Keith Simpson, Curator of the Gordon Museum, for kindly helping us to locate the stone and giving permission for part of it to be re-examined.

P. D. Griffiths, M.B., B.Ch., Senior Registrar, Guy's and Lewisham Hospitals, London.

R. G. Huntsman, M.D., M.R.C.P., Chemical Pathologist, Memorial Hospital, Peterborough.

C. G. A. Thomas, B.M., M.R.C.P., Consultant Bacteriologist, Norfolk and Norwich Hospital, Norwich.

\section{REFERENCES}

1 Wollaston, W. H. (1810). Phil. Trans. B, 100, 223.

Harrison, G. A. (1957). Chemical Methods in Clinical Medicine, 4th ed. Churchill, London.

3 Smith, I. (1960). Chromatographic and Electrophoretic Techniques, vol. 1. Heinemann, London.

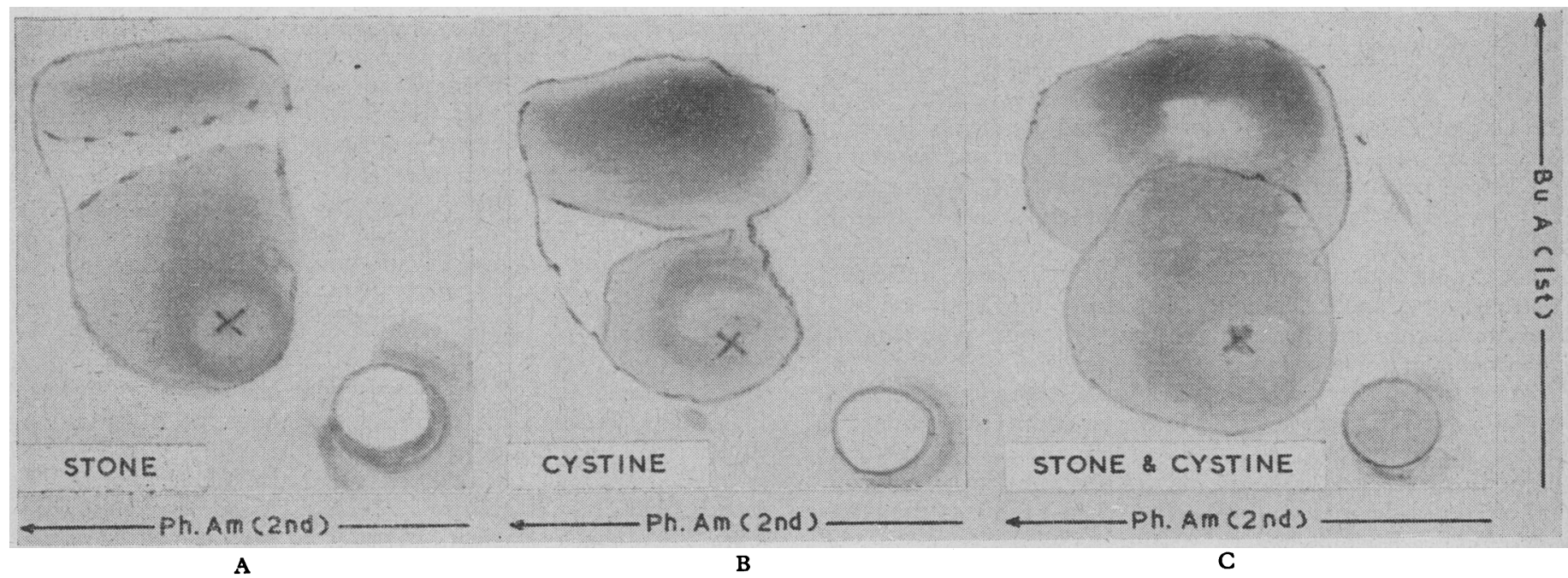

Two-way paper chromatography of an acidic solution of the urinary calculus (A), a solution of cystine (B), and a mixture of solutions A and B (C), The figures

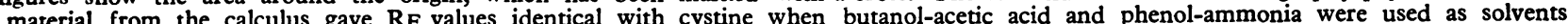

